\title{
Separação de Hidrocarbonetos Alifáticos e Aromáticos por CFG utilizando a fase estacionária OV-275 a diferentes temperaturas
}

Júlio Lopes Rodrigues a

M. Teresa Vilhena ${ }^{a}$ Eva Jacobsohn Raposo a

\section{INTRODUÇÃO}

Diversos produtos de interesse industrial são constituídos por misturas de hidrocarbonetos aromáticos e alifáticos e podem ser utilizados quer como solventes, diluentes ou com outras funçð̋es. As indústrias de tintas, vernizes e produtos afins bem como de detergentes, têxteis, etc., aplicam estes produtos.

Em estudos anteriores $[1,2]$ utilizou-se, para a separação de hidrocarbonetos aromáticos em "hexano", respectivamente colunas com os enchimentos de Porapak $\mathrm{Q}$ e de OV-275 a $10 \%$ sobre Chromosorb P AW.

No presente trabalho, estudou-se a separação de um maior número de hidrocarbonetos aromáticos e alifáticos (n-alcanos) por cromatografia em fase gasosa (C.F.G.), utilizando uma coluna com a fase líquida OV-275 a $20 \%$ sobre Chromosorb P AW-DMCS e a influência da temperatura na separação destes compostos.

\section{PARTE EXPERIMENTAL}

\section{Equipamento}

- Cromatógrafo de fase gasosa Varian 3700 equipado com detector de ionização de chama

- Registador-Integrador Hewlett Packard 3390-A

\section{Reagentes}

- n-alcanos, de metano $\left(\mathrm{C}_{1}\right)$ a n-hexadecano $\left(\mathrm{n}-\mathrm{C}_{16}\right)$ - hidrocarbonetos aromáticos: benzeno, tolueno, etilbenzeno, o-xileno, m-xileno, p-xileno, cumeno, pseudocumeno, mesitileno

\section{Coluna cromatográfica}

Fase líquida OV-275 a 20\% sobre Chromosorb P AW-DMCS, 80-100 "mesh", em tubo de aço inox de $2 \mathrm{~m} \times 1 / 8^{\prime \prime}(3,17 \mathrm{~mm})$.

O enchimento da coluna foi preparado por diluição da fase líquida em acetona, adição do suporte seguida de evaporação do solvente a pressão reduzida em evaporador rotativo. $\mathrm{O}$ enchimento preparado foi colocado no tubo de aço, previamente lavado, com auxílio de funil e vibração.

\section{Condições operacionais}

Azoto: $10 \mathrm{~cm}^{3} \mathrm{~min}^{-1}$

Caudais dos gases

\section{Ar: $400 \mathrm{~cm}^{3} \mathrm{~min}^{-1}$}

Hidrogénio: $30 \mathrm{~cm}^{3} \mathrm{~min}^{-1}$

Temperaturas do forno: $\begin{array}{ll} & 100^{\circ} \mathrm{C} \\ & 125^{\circ} \mathrm{C} \\ & 150^{\circ} \mathrm{C} \\ & 170^{\circ} \mathrm{C}\end{array}$

\section{RESULTADOS E DISCUSSÃO}

Variação do índice de retenção função da temperatura

Após condicionamento da coluna, determinaram-se, com base nos tempos de retenção dos n-alcanos, os indices de retenção dos diferentes hidrocarbonetos aromáticos. Na Tabela 1 figuram os valores dos índices de retenção obtidos às temperaturas de $100^{\circ} \mathrm{C}, 125^{\circ} \mathrm{C}$, $150^{\circ} \mathrm{C}$ e $170^{\circ} \mathrm{C}$.

TABELA 1

Índices de retenção função da temperatura

\begin{tabular}{|l|cccc|}
\hline \multicolumn{1}{|c|}{$\begin{array}{c}\text { Temperatura } \\
\text { Composto }\end{array}$} & $100^{\circ} \mathrm{C}$ & $125^{\circ} \mathrm{C}$ & $150^{\circ} \mathrm{C}$ & $170^{\circ} \mathrm{C}$ \\
\hline Benzeno & 1200 & 1259 & 1323 & 1391 \\
Tolueno & 1278 & 1344 & 1405 & 1471 \\
Etilbenzeno & 1341 & 1411 & 1474 & 1543 \\
m-Xileno & 1350 & 1423 & 1477 & 1546 \\
p-Xileno & 1347 & 1419 & 1474 & 1543 \\
o-Xileno & 1409 & 1491 & 1553 & 1625 \\
Cumeno & 1361 & 1437 & 1488 & 1559 \\
pseudocumeno & 1467 & 1553 & 1610 & 1690 \\
mesitileno & & 1478 & 1529 & \\
\hline
\end{tabular}

Pela análise desta tabela pode-se verificar que o benzeno apresenta um índice de retenção igual ao do n-dodecano $\left(n-\mathrm{C}_{12}\right)$ enquanto que a $150^{\circ} \mathrm{C}$ este valor é ligeiramente superior ao do n-tridecano $\left(\mathrm{n}-\mathrm{C}_{13}\right)$ e a $170^{\circ} \mathrm{C}$ ligeiramente inferior ao do n-tetradecano $\left(\mathrm{n}-\mathrm{C}_{14}\right)$. Aumentos semelhantes dos índices de retenção se verificam para os restantes hidrocarbonetos aromáticos.

$\mathrm{O}$ aumento do índice de retenção, com o aumento da temperatura, nos compostos aromáticos é muito marcado nesta coluna. Facto idêntico encontra-se descrito por diferentes autores $[3,4]$, especialmente com fases polares. 


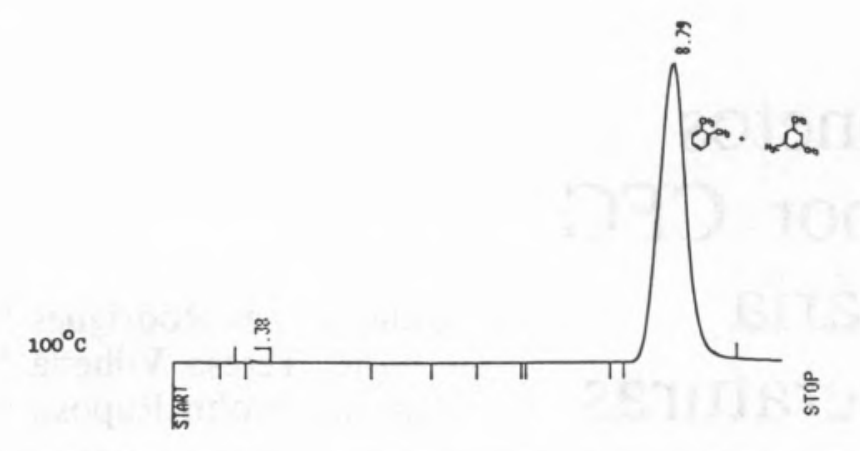

$125^{\circ} \mathrm{C}$
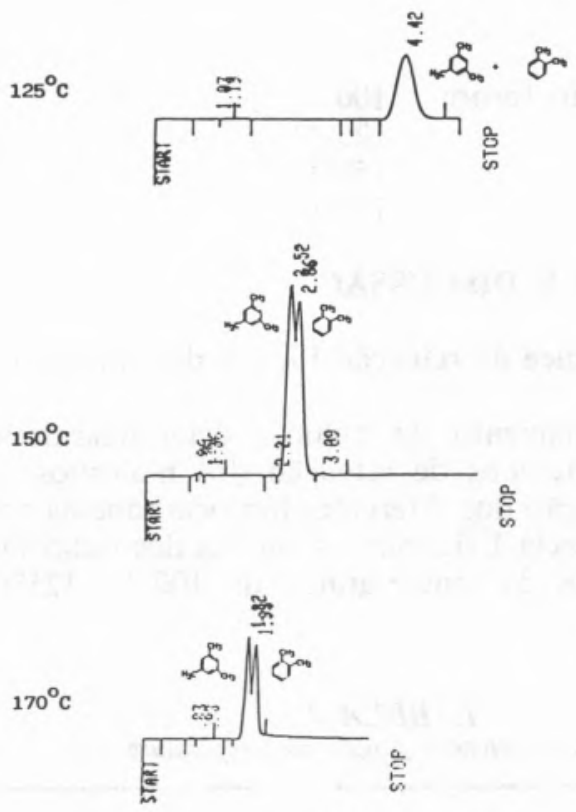

FIGURA 1

Cromatograma da mistura de mesitileno e o-xileno às temperaturas de $100^{\circ} \mathrm{C}, 125^{\circ} \mathrm{C}, 150^{\circ} \mathrm{C}$ e $170^{\circ} \mathrm{C}$

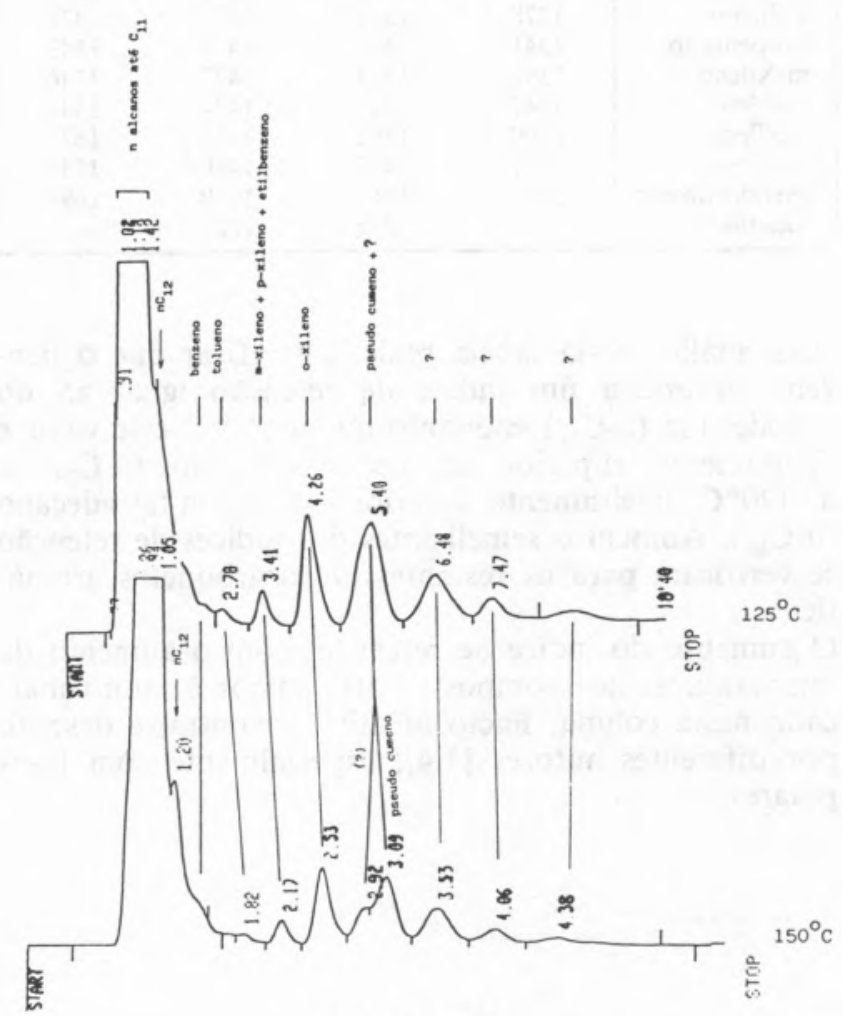

FIGURA 2

Cromatogramas de "White Spirits" às temperaturas de $125^{\circ} \mathrm{C}$ e $150^{\circ} \mathrm{C}$
Separação por CFG de mesitileno e o-xileno em função da temperatura

A fim de estudar melhor o comportamento da coluna de OV-275 face à variação da temperatura foram escolhidos os hidrocarbonetos o-xileno (1,2-dimetilbenzeno) e mesitileno (1,3,5-trimetilbenzeno) para analísar a influência deste parâmetro na separação cromatográfica, quando injectados separadamente e em mistura. $\mathrm{Na}$ Tabela 2 apresentam-se os valores dos tempos de retenção obtidos respectivamente a $100^{\circ} \mathrm{C}, 125^{\circ} \mathrm{C}$, $150^{\circ} \mathrm{C}$ e $170^{\circ} \mathrm{C}$.

TABELA 2

Tempos de retenção (em minuto), de mesitileno e o-xileno a diferentes temperaturas

\begin{tabular}{|c|c|c|}
\hline Temperaturas & Mesitileno & o-Xileno \\
\hline $100^{\circ} \mathrm{C}$ & 8,87 & 8,80 \\
\hline $125^{\circ} \mathrm{C}$ & 4,35 & 4,50 \\
\hline $150^{\circ} \mathrm{C}$ & $.2,52$ & 2,66 \\
\hline $170^{\circ} \mathrm{C}$ & 1,82 & 1,99 \\
\hline
\end{tabular}

Verifica-se que o tempo de retenção do mesitileno é superior ao do o-xileno a $100^{\circ} \mathrm{C}$, havendo inversão desta ordem às outras temperaturas.

$\mathrm{Na}$ Figura 1 estão representados os cromatogramas obtidos com a mistura dos dois hidrocarbonetos, às temperaturas em estudo.

A mistura destes dois hidrocarbonetos não se resolve nos seus componentes a $100^{\circ} \mathrm{C}$ e a $125^{\circ} \mathrm{C}$, enquanto que a $150^{\circ} \mathrm{C}$ se esboça separação, que melhora a $170^{\circ} \mathrm{C}$.

\section{Análise de amostras de "White Spirits"}

Como aplicação do método desenvolvido efectuou-se a análise de amostras de "White Spirits", apresentando-se na Figua 2 dois cromatogramas de uma amostra a duas temperaturas.

A análise destes cromatogramas permite verificar que o pico com o tempo de retenção $5,4 \min \left(125^{\circ} \mathrm{C}\right)$ se resolve em dois picos a $150^{\circ} \mathrm{C}$.

\section{Referências}

[1] Rodrigues, J.L.; Vilhena, M.T.; Raposo, E.J., 8. ${ }^{\circ}$ Encontro da S.P.Q., C 133. Universidade do Minho, Braga (1985)

[2] Rodrigues, J.L.; Raposo, E.J.; Vilhena, M.T., $10{ }^{\circ}$ Encontro da S.P.Q., A-20. Universidade do Porto, Porto (1987)

[3] Jennings, W., Gás Chromatography with glass capillary columns, Academic Press., New York (1973)

[4] Tranchant, J., Manuel Pratique de Chromatographie en fase gazeuse, 3. ${ }^{a}$ Ed., Masson, Paris (1982) 